\title{
AfricArXiv
}

\section{Enhancing African \\ Research Visibility \\ Through Use of \\ Repositories}

Jo Havemann ${ }^{1}$, Mark Hahnel ${ }^{2}$, Mark Snyders ${ }^{3}$, Stephanie Kitchen ${ }^{4}$, Joy Owango 5

${ }^{1}$ Access 2 Perspectives, AfricArXiv, ${ }^{2}$ Figshare, ${ }^{3}$ University of the Western Cape,

${ }^{4}$ International African Institute, ${ }^{5}$ TCC Africa

Published on: Feb 05, 2021

License: Creative Commons Attribution 4.0 International License (CC-BY 4.0). 
Sub-Saharan Africa [is said to] account [s] for $13.5 \%$ of the global population but less than $1 \%$ of global research output.

Part of the problem is that there is low visibility of its research output.

Open access repositories have created a paradigm shift in enhancing African research output.

Where are these repositories and how can we take advantage of them?

How should African researchers make use of these repositories to increase their visibility?

Watch the recording of the panel discussion: 